\title{
A Perspective on Postharvest Physiology and Biochemistry
}

\author{
Roger J. Romani \\ Department of Pomology, University of California, Davis, CA 95616
}

The scientific work of Professor Jacob B. Biale spanned about four decades. His accomplishments were notable. So too have been the advancements in postharvest physiology and biochemistry as a whole. It may be said that the field is acquiring the status of a discipline with frequent reviews, Gordon Research Conferences, a forthcoming journal, and a set of operative paradigms.

Identification with an evolving field of research and some sense of its dynamics and direction(s) can be gained from a quasi-historical perspective. That is the aim of this brief overview. The exercise is neither complete nor unbiased. What follows is a narrow selection of scientific papers, chosen in particular for the paradigm(s) or research construct(s) they have fostered. The overview will, at best, elicit differences of opinion and encourage other postharvest perspectives.

\section{HISTORICAL CONTEXT}

Preoccupation with the maintenance of freshly harvested food can be traced to historic cultures and, with the aid of archeology and imagination, even to prehistoric times. The modem scientific investigative trend, however, began early in the 20th Century with the researches of Allen, Gane, Hansen, Hulme, Joslyn, Kertesz, Kidd, Neljubow, Nitch, Overholser, Wardlow, West, and others, who established the foundations of our field. An invaluable source for this early perspective is the excellent monograph "La Vie des Fruits" by Ulrich (1952). The French text need not deter the non-French reader, for the book is replete with self- or nearly self-explanatory tables and figures that illustrate the essential principles. I shall rely on Ulrich to provide the perspective to 1950 and turn to a synoptic, decade-by-decade view of the subsequent 40 years.

Received for publication 10 Sept. 1990. Taken from a presentation made 12 July 1990 at the Gordon Research Conference on Postharvest Physiology in the Thursday evening session dedicated to Professor Jacob B. Biale. I wish to thank the organizers of the 1990 Gordon Conference for the opportunity to present this paper and to colleagues and reviewers who offered many helpful suggestions, though they themselves may not necessarily have agreed with some of the concepts espoused. The cost of publishing this paper was defrayed in part by the payment of page charges. Under postal regulations, this paper therefore must be hereby marked advertisement solely to indicate this fact.

\section{THE LAST FOUR DECADES}

1950s. For those approaching retirement, the 1950s have special meaning, for they coincide with our own scientific beginnings. Postharvest physiology came of age in that decade when it was chosen as a topic for review in the first volume of the Annual Reviews of Plant Physiology (Biale, 1950), and featured on a cover-page article (Fig. 1) in Scientific American (Biale, 1954).

Three scientific papers of this decade come readily to mind. The first, by Millered et al. (1953), attributed the respiratory climacteric to dysfunctional energetic, i.e., uncoupling of mitochondria. This pioneering study was made possible by the advent of high-speed centrifuges only a few years before. The second paper, by Pearson and Robertson (1954), attributed the climacteric not to uncoupling, but to the energy demands of anabolic processes accompanying ripening. These two papers thus ascribed the climacteric to quite different energetic relationships: metabolic inefficiency vs. energy demand. The dilemma is still not fully resolved. Nevertheless, the conceptual connection between energetic and the climacteric has remained an important facet of research in postharvest physiology.

The third paper, by Biale et al. (1954), reported their careful measurement of the onset of the respiratory climacteric and eth-

\section{SCIENTIFIC AMERICAN}

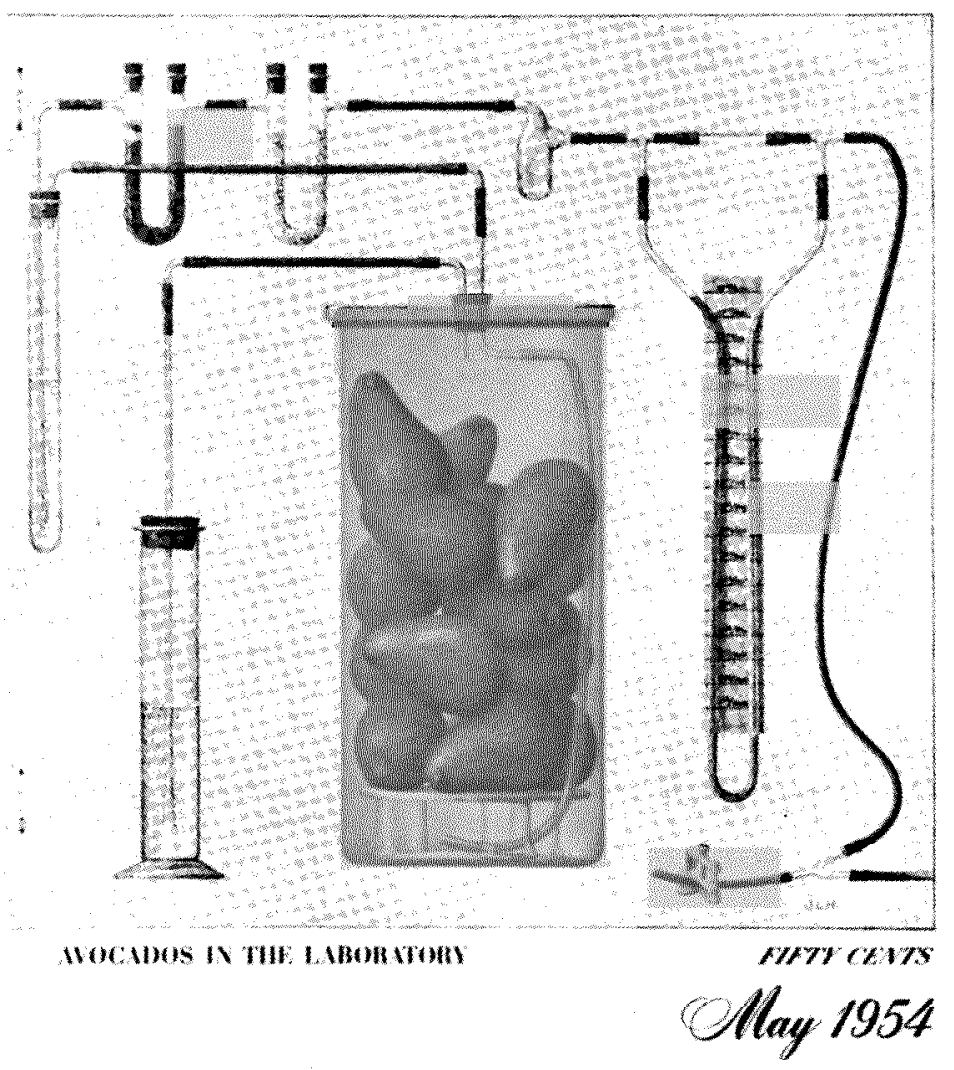

Fig. 1. From "The Ripening of Fruit," by Jacob B. Biale (1954). Copyright by Scientific American Inc. All rights reserved. 
ylene production by some 14 different fruits, including apple, pear, banana, and other commonly studied fruits, as well as lessstudied tropicals such as cherimoya and papaya. The work was facilitated by two technological innovations: 1) the combination of an automatic gas sampling valve and paramagnetic oxygen analyzer (Young and $\mathrm{Bi}$ ale, 1951), believed to be the first such automated system employed in our field, and 2) a new, and for then, very sensitive manometric system for the measurement of ethylene (Young et al., 1952). Via their analyses, Biale et al. (1954) classified several fruits as climacteric or nonclimacteric, the latter characterized by the absence or delay of autocatalytic ethylene production. Although often cited for this clear but not necessarily novel distinction of fruit types, the paper's more lasting and controversial influence derives from the last of six summary points, e.g., "... native ethylene is a product of the ripening process rather than a causal agent." This concept fueled a controversy yet to be satisfactorily resolved.

These few papers are hardly representative of the gamut of postharvest research conducted in the 1950s. They did, however, address questions that have remained central to physiological research in our field.

1960s. One can readily point to several influential papers that appeared in this decade. Polygalacturonase (PG) has been known for some years, but in his own study of tomato PG, Hobson (1963) provided an inkling of what was to become a major research thrust during the 1980s. Lieberman et al. (1965) alerted us to the fact that methionine was the ethylene precursor and thereby provided the basis for subsequent definitive research on the pathway of ethylene biosynthesis. The work of Burg and Burg (1965) was especially noteworthy, as it established hypotheses regarding sites and modes of ethylene action and inhibition that still prevail. Their use of hypobaric storage conditions (Burg and Burg, 1966) provided seemingly incontrovertible evidence for the essentiality of ethylene to fruit ripening.

Meanwhile, Dostal and Leopold (1967) demonstrated that the respiratory climacteric was not all that it had been presumed to be. Since its discovery and naming some 45 years before by F. Kidd and C. West, the climacteric had occupied a central position as the metabolic event that drove all postharvest physiological and biochemical changes. Making clever use of gibberellic acid, Dostal and Leopold (1967) demonstrated that pigment formation in ripening tomatoes could, however, be disjoined from the climacteric respiratory trend. Subsequent studies established that yet other facets of ripening could be separated from the respiratory climacteric. Accordingly, the physiological/biochemical cause(s) for the climacteric remain unexplained.

In 1966; Lance et al. demonstrated that especially well-coupled mitochondria could be isolated from fruit at the climacteric peak. That observation, along with electron microscopic evidence by Bain and Mercer (1964) showing mitochondria to remain structurally unimpaired well past the climacteric, and evidence by Young and Biale (1967) that phosphorylation continued throughout the climacteric discredited "uncoupling" as a cause of the respiratory burst.

In contrast, the connection between protein synthesis and ripening was placed on a firm footing in the 1960s. Credit should go to A.C. Hulme and his colleagues at the Ditton Laboratory, Long Ashton, for having observed, in the early 1930s, what seemed to be an unlikely but real increase in cellular proteins coincident with the climacteric in apples. This work was revived after World War II, but the vagaries of "wet-chemistry" made conclusive results difficult. Using radio-labelled precursors, Richmond and Biale confirmed the presence of increased protein synthesis (1966) and increased RNA synthesis (1967) coincident with the onset of the respiratory climacteric. These studies, subsequently confirmed by many others, entrenched the connection between macromolecular synthesis and ripening that was to stimulate much postharvest research in the 1980s and today.

A final commentary on the 1960 s pertains to the coincidental appearance of three postharvest papers in the same July 1968 issue of Plant Physiology. The first, by Frenkel et al. (1968), reported the use of cycloheximide to confirm the essentiality of protein synthesis to the progress of ripening. Moreover, these authors used emergent electrophoretic techniques to identify malic enzyme among the more prominent new proteins. The second paper, by Hulme et al. (1968), received appreciably less attention, although it demonstrated a significant increase in malic enzyme, the "malate effect," during the climacteric in apples. It seems unfortunate that this interesting lead has not been followed more vigorously. Reality, if not modesty, compels me to acknowledge that the third paper, (Romani et al., 1968), has remained quite obscure. This study demonstrated that, in terms of respiration, mitochondrial protein synthesis, and mitochondrial energetic, ripening was characterized by a loss of compensatory or homeostatic potential. I shall return to this theme at the end.

1970s. Early in this decade, Lyons and Raison (1970) proposed that a functional connection existed between phase transitions in the lipids of bilayer membranes and low temperature injury-an intriguing concept that has held sway for many years. Although there have been differences of opinion regarding the interpretation of Arrhenius plots, advances in analytical techniques, including electron spin resonance and differential scanning calorimetry, have reaffirmed the importance of the initial concept.

Also early in the 1970s, a short paper by McMurchie et al. (1972) familiarized us with the beautifully simple and ingenious use of propylene to elicit a measurable (as ethylene production) olefin-induced response. It was the type of experiment that caused many of us to wonder why we had not thought of it. The same paper introduced the terminology
System I and System II ethylene production. While helping to make clear the distinction between basal level (System I) and autocatalytic (System II) ethylene production, the terms have, on occasion, been mistaken to imply that the two widely different levels of ethylene production were the result of two different systems. Such evidence does not exist. [This assertion may be questioned in view of the recent evidence and hypothesis of Yip et al. (1990) that there may be two ACC synthase genes, one activated by ripening and the other by wounding.]

The mid-seventies saw the near culmination of 20 years of mitochondrial research vis-a-vis the climacteric. In a particularly intriguing study, Solomos and Laties (1976) observed that, among several fruits and vegetables tested, an ethylene-stimulated climacteric occurred only in those that also exhibited the cyanide-resistant alternative electron transport pathway. It appeared as if ethylene mediated the flow of electrons through the alternative path and that its absence precluded the climacteric response. With this work, the connection between mitochondria and the respiratory climacteric may have reached its zenith, for, shortly thereafter, Theologis and Laties (1978) observed that even though avocado fruit did indeed possess the alternative pathway, it was not operative during the normal climacteric. While the latter observation surely dampened the enthusiasm for fruit mitochondrial research, it left unexplained the energetic basis of the climacteric, or the role, if any, of the alternative pathway that exists in the mitochondria of many fruit cells.

A key paper appearing in the mid-1970s effectively capped $>40$ years of quantitative research on protein synthesis and the climacteric. Using dual-label techniques and gel electrophoresis, Brady and O'Connell (1976) demonstrated that even with the most sensitive available methods, one could not discern uniquely new proteins (enzymes) coincident with the increase in respiration and protein synthesis of ethylene-treated banana fruit slices. In the paper were two other observations that, in retrospect, were of notable importance. First was the finding that as much as $50 \%$ of the protein in the ripening tissues "turned-over" every $24 \mathrm{~h}$, thus emphasizing the dynamic nature of macromolecular synthesis in fruit cells. Second was the observation that whereas a 12-h exposure to ethylene induced a lasting increase in respiration and protein synthesis, i.e., the climacteric, a 6-h exposure produced an initially similar but only transient increase in these two functions. As discussed elsewhere (Romani, 1984), this observation causes one to question whether the initial ethylene-induced increase in respiration and protein synthesis is a direct effect or a counteractive response. That is, is the initial respiratory increase the beginning of the climacteric and ripening, or is it a corrective homeostatic response to some stress effect of ethylene, with ripening being a secondary phenomenon, but only if exposure to ethylene persists?

Three papers of the late 1970s proved to 
have been especially opportune. Tigchelaar et al. (1978) strongly promoted the popularity of polygalacturonase, ascribing to it a causative role in initiating ethylene production and the manifold events associated with ripening. This concept, enhanced by the effective use of nonripening mutants, but based primarily on circumstantial evidence, was to persist and be especially influential in the next decade.

Rattanapanone et al. (1978) did what seemed then to be the near impossible. They isolated messenger RNA from green and ripe tomato fruit, translated the mRNA in vitro, and demonstrated the appearance of new messages in the ripening tissues. This observation, and others like it soon to follow, provided an experimental basis with which to explore the now accepted notion that senescence (ripening) is programmed and, therefore, controllable at the molecular level.

Finally, at the end of the decade, Adams and Yang (1979) brought l-amincyclopropane-1 -carboxylic acid (ACC) to postharvest physiology. With this paper, and others that followed from Yang's and other laboratories, the search for the mechanism of ethylene biosynthesis was effectively ended. The mechanism of ethylene action, however, remains enigmatic.

1980s. ACC, ACC synthase, ethylene forming enzyme (EFE), and related aspects of ethylene biosynthesis have been much a part of postharvest research of the 1980s. Nonetheless, it is probably fair to say that the 1980s are symbolized by the flourishing of molecular biology. Progress in several laboratories has been exciting and phenomenal with the thrust still too recent and overwhelming to encourage summarization. However, three papers come most readily to mind. Early in the decade, Christoffersen and Laties (1982) firmed the connection between ethylene action and gene expression by effectively associating an ethylene-induced increase in polysomes with the appearance of new messenger RNA, thus reinforcing the earlier observation by Rattanapanone et al. (1978).

Two papers appearing near the end of the 1980s seem emblematic of this "molecular" decade. In both studies, structural genes and promoter regions were extracted from tomato cells, some reassembled backward, others reassembled with parts from different cultivars. The "new" genes were put back in tomato cells, plants regenerated, and fruit obtained in which chimeric or antisense genes proved stable and some phenotypic effects manifest. Thus, Smith et al. (1988) and Giovannoni et al. (1989) accomplished with antisense and chimeric genes, respectively, what would have been truly unbelievable only a few years before.

One must not leave the impression that important research in postharvest physiology during the 1980s was confined to aspects of ethylene biosynthesis and molecular controls. Notable advances were made on many fronts, including the use of short-term high $\mathrm{CO}_{2}$ treatments, calcium-calmodulin interdependency, cell wall metabolism, elicitors of ethylene biosynthesis, and polyamides, to name a few. Time and new insights will help delineate the especially influential studies.

\section{RETROSPECT}

Can anything be learned from this sketchy sojourn through 40 years of postharvest research? Perhaps. It is immediately obvious that one cannot hope to delineate the most important discoveries with any semblance of thoroughness or objectivity. The exercise, however, provides a sense of continuity within different lines of investigation with waxing and waning of each and the presence of interconnections. A research flow chart (Fig. 2) helps visualize the flux of investigative trends. The choice of principal topics and their "popularity," i.e., width of line at any one time, is arbitrary. At the bottom of the chart are listed some of the specific techniques that have often spurred particular lines of investigation.

The lines of research have experienced various vicissitudes. Excitement surrounding the connection(s) between membrane composition, phase-transitions, and low-temperature injury has waned, not because the original concept was disproved, but because biological realities were found to be more complex than imagined. Similar constraints may be said to apply to the mitochondriaenergetics-climacteric connection. The decline of interest in this avenue is not attributable to proven unimportance but to an apparent dearth of exploitable concepts.

Plant mitochondria have received little attention of late, but they exist and function in senescent fruit cells. Mitochondria are likely the principal source of climacteric respiration, also the mitochondrial cyanide-resistant respiration is present and often increases with ripening of many fruit. What is needed is a paradigm shift, some new information and an altered construct, to engender a renewed thrust of research on mitochondria. New and promising methodological approaches in the offing include monoclinal antibodies for the alternative oxidase (Elthon et al., 1989), the use of microcalorimetry to discern metabolic efficiencies and pathways (Criddle et al. 1988), and the use of self-restoring fruit mitochondria (Romani and Howard, 1982) to discern and study physiologically related changes in intrinsic mitochondrial functions.

In some instances, overemphasis on a given phenomenon may have engendered a certain weariness with the subject and premature loss of favor. That may have been the case for the climacteric. For $>40$ years after its discovery by F. Kidd and C. West, the climacteric was the cornerstone phenomenon of postharvest research. Then, with evidence that it could be disjoined from other ripening changes, the climacteric lost favor, to be replaced by programmed senescence as the engrossing biological context for ripening. Nonetheless, the climacteric exists as the most readily discernable index of metabolic function associated with ripening. What is its basis? A rationalization of this fundamental question in the context of cellular homeostasis has been suggested (Romani, 1984), but the underlying mechanisms remain a mystery.

Is the popularity of research on PG through much of the 1980s now subject to de-emphasis, as suggested in Fig. 2? The probability that this could happen is enforced by the observations that neither the insertion of antisense PG gene in normal (wild type) tomatoes nor an active, chimeric PG gene in nonripening Rin tomatoes had the anticipated effect on softening, even though PG was largely obliterated in the first instance and manifestly present in the second. Thus, the centrality of PG in ripening - a construct stemming from the 1970 s and highly tractable to molecular techniques-is in doubt. One must hasten to acknowledge that counterevidence for any construct, be it uncoupling or the alternate path or PG, does not
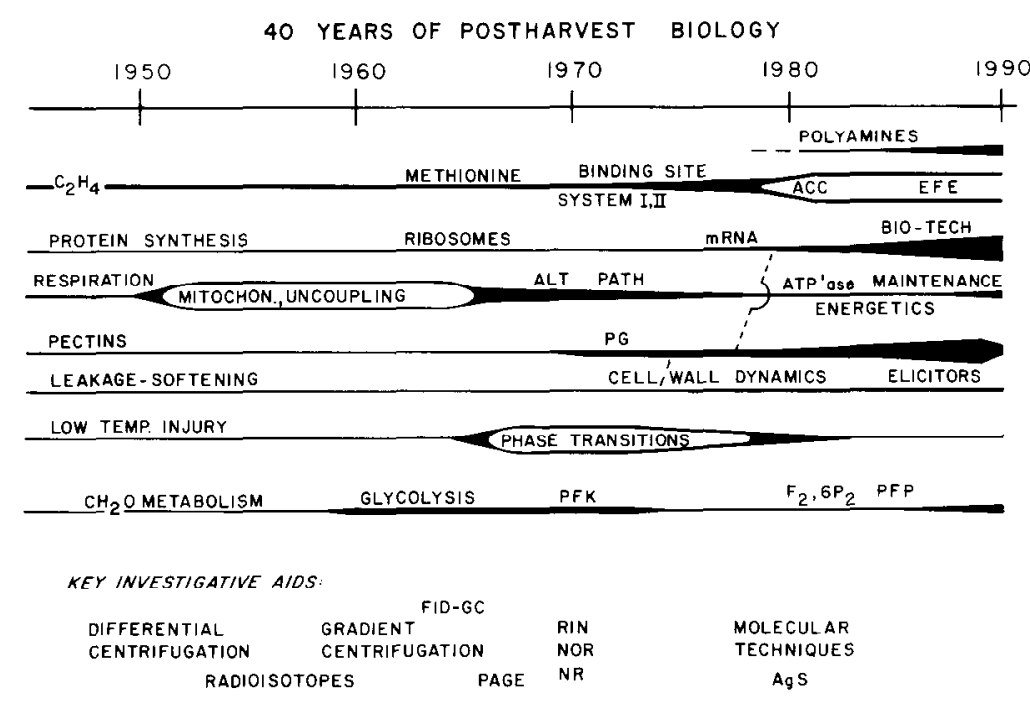

Fig. 2. A flow chart depicting the evolution, relative popularity (thickness of line), and some interconnections (---) among principal research topics in postharvest biology, 1950-90. A few key investigative and technical aids are noted. 
negate the logic of the original thinking (based on evidence then at hand) nor the value of the research engendered by it.

\section{FUTURISMS-THE 1990s}

While Fig. 2 may provide some temporal perspective and sense of flow and interconnection, it contains few if any clues for the future. One cannot simply extrapolate present trends into the 1990s. That, as we all know, is not the way of scientific progress. As so aptly reasoned by Kuhn (1962) in his "Structure of Scientific Resolutions," it is the new, unexpected paradigm that provides stimulus for much connection-making or, as he calls it, "puzzle solving" research. For instance, ACC and the resolution of ethylene's biosynthetic pathway has fostered a decade of connection-making research; an effort that will surely continue. Still at issue is ethylene's mode of action. An important question for the present is whether the metalcomplex, binding-site construct that forms the basis for much research on the mode of ethylene action is the only or the best construct for resolving this enigmatic aspect of ethylene physiology. A new and promising paradigm in this area would surely have a dramatic impact on the direction of ethylenerelated research.

Constraints in developing new paradigms or applying new biological insights to postharvest research often arise from the complex way(s) nature makes use of seemingly straightforward phenomena. Take, for example, the alternative path or action of the PG gene. These phenomena have been effectively investigated and are quite well understood. However, research has fallen short of providing the anticipated resolution of physiological role(s). This failure largely may be attributed to the lack of an appropriate theoretical construct or insight connecting the phenomenon to its function in nature.

In his mini-review, "Success and Limitations of Molecular Biology," Holliday (1988a) emphasizes the importance of theoretical constructs in guiding research. Holliday points to the historic fact that the collinearity of DNA base sequence with amino acid sequence and the existence of transfer RNAs and messenger RNA had been predicted before their discovery. These constructs provided impetus and direction in the first highly successful decades of molecular biology. In contrast, Holliday observes, current molecular biology is often driven by the very power of its techniques without adequate reference to a theoretical or conceptual framework. In particular, he notes the need for a theory of epigenetics, the latter defined as the "study of the mechanisms which turn genes on and off during the developmental process...." That, it seems to me, is very much what is needed in research to resolve the molecular bases and the molecular controls that pertain to fruit senescence.

With that as background, and in a very speculative vein, I would suggest three likely directions for research in postharvest physi- ology/biochemistry in the forthcoming decade. The first is based on the potential metabolic interconnectedness of several postharvest physiological/biochemical phenomena, the second on the promise of molecular biotechnology, and the third on a most basic function of living cells.

Senescence, ethylene, polyamides, and epigenetics. DNA methylation is Holliday's favored epigenetic mechanism. It is one that has special appeal in postharvest physiology because of the metabolic interconnection between ethylene production, polyamine synthesis, and methylation-all via a common precursor, S-adenosylmethionine. Given 1) the well-established positive influence of ethylene on plant cell senescence, 2) the evidence that polyamides delay plant senescence, 3 ) the variety of methylation reactions in plant cells for which S-adenosylmethionine is the methyl donor, and 4) the probable epigenetic role of DNA methylation, it would not be surprising if this nexus received considerable attention in the 1990s.

Biotechnological fix(es). Even though experiments with antisense and chimeric PG genes did not result in the anticipated control of ripening, these elegant studies established beyond doubt the feasibility of applying biotechnology to postharvest research. Moreover, even though antisense PG did little to deter softening, it did apparently affect the size of the PG breakdown products and lessen the susceptibility of the tomato tissue to pathogenic infection. In short, biotechnology works. Driven by potential economic benefits, this technology likely will be successfully applied in the 1990s. It is, after all, already beyond exploratory science and in the realm of exploitable technology.

Beyond biotechnology-maintenance metabolism. If one accepts, as most do, that programmed senescence is the basis for postharvest development, and if one assumes, and recent progress seems to justify the assumption, that antisense and related biotechnologies will bring some epigenetic control of senescence, what next? If' "biotech" makes it possible to stop or start ripening on demand, can there be a great extension of storage and marketing life? Not necessarily. Fruits and other harvested tissues are living and dynamic and will change with time even if programmed ripening is stopped. Moreover, the direction of change is likely to be undesirable, for it is difficult to escape the second law of thermodynamics: Things go downhill. Thus, putting epigenetic control of ripening to practical use will require effective maintenance of the tissues over extended periods.

Maintenance is the living cell's energydemanding counteroffensive to the second law of thermodynamics. As put by Holliday (1988b) with respect to mammalian aging, "the overall aging process is the result of the eventual failure of maintenance mechanisms." The same rule applies to the aging of harvested plant tissues. Elsewhere (Romani, 1984, 1987), evidence is cited to confirm that fruit cells exhibit maintenance, or homeostasis. The 1990s may see a reexam- ination of classical postharvest techniques, those involving temperature, humidity, modified atmospheres, etc., not solely with traditional objectives of suppressing postharvest metabolism, but keeping in mind its essentiality for maintenance. The intent should be to maximize the lifetime and inherent quality of fruit and vegetables by exploiting the built-in corrective, stabilizing propensity of living tissue.

\section{SUMMARY}

Whatever its future directions, research in postharvest physiology and biochemistry promises to be an increasingly well-delineated field of scientific inquiry. As such, it provides a set of paradigms to guide our investigations and, importantly, a group of colleagues and forums, such as the Gordon Conference, to share and test our findings and ideas. It is a context, a milieu, that engenders enthusiasm for one's research-much like that experienced in the laboratory of Professor Biale by the many who were fortunate to have worked with him.

\section{Literature Cited}

Adams, D.O. and S.F. Yang. 1979. Ethylene biosynthesis: Identification of 1-aminocyclopropane-1 -carboxylic acid as an intermediate in the conversion of methionine to ethylene. Proc. Natl. Acad. Sci. 76(1):170-174.

Bain, J.M. and F.W. Mercer. 1964. Organization resistance and the respiratory climacteric. Austral. J. Biol. Sci. 17:78-85.

Biale, J.B. 1950. Postharvest physiology and biochemistry of fruits. Annu. Rev. Plant Physiol. $1: 183-206$.

Biale, J.B. 1954. The ripening of fruit. Scientific Amer. 190:40-44.

Biale, J.B. Young, R. E., and A.J. Olmstead. 1954. Fruit respiration and ethylene production. Plant Physiol. 29:168-174.

Brady, C.J. and P.B.H. O'Connell. 1976. On the significance of increased protein synthesis in ripening banana fruit. Austral. J. Physiol. 3:301310.

Burg, S.P. and E.A. Burg. 1965. Ethylene action and the ripening of fruits. Science 148:11901196

Burg, S.P. and E.A. Burg. 1966. Fruit storage at subatmospheric pressures. Science 153:314-315.

Christoffersen, R.E. and G.G. Laties. 1982. Ethylene regulation of gene expression in carrots. Proc. Natl. Acad. Sci. 79:4060-4063.

Criddle, R. S., R.W. Breidenbach, E.A. Lewis, D.J. Eatough and L.D. Hansen. 1988. Effects of temperature and oxygen depletion on the metabolic rates of tomato and carrot cell cultures and cuttings measured by calorimetry. Plant Cell and Env. 11:695-701.

Dostal, H.C. and A.C. Leopold. 1967. Gibberellin delays ripening of tomatoes. Science 158:1579-1580

Elthon, T. F., R.L. Nickels, and L. McIntosh. 1989. Monoclinal antibodies to the alternative oxidase of higher plant mitochondria. Plant Physiol. 89:1311-1317.

Frenkel, C., I. Klein, and D.R. Dilley. 1968. Protein synthesis in relation to ripening of pome fruits. Plant Physiol. 43:1146-1153.

Giovannoni, J.J., D. DellaPenna, A.B. Bennett, and R.L. Fischer. 1989. Expression of chimeric polygalacturonase gene in transgenic rin (ripening inhibitor) tomato fruit results in poly- 
uronide degradation but not fruit softening. The Plant cell 1:53-63.

Hobson, G.E. 1963. Polygalacturonase in normal and abnormal tomato fruit. Biochem. J. 92:324.

Holliday, R. 1988a. Successes and limitations of molecular biology. J. Theor. Biol. 132:253-262.

Holliday, R. 1988b. Toward a biological understanding of the aging process. Perspectives in Biol. and Medicine 32:109-123.

Hulme, A. C., M.J.C. Rhodes, T. Galliard, and L.S.C. Wooltorton. 1968. Metabolic changes in excised fruit tissue. IV. Changes occurring in discs of apple peel during the development of the respiration climacteric. Plant Physiol. 43:1154-1161.

Kuhn, T. 1962 (2nd ed. 1970). The structure of scientific revolutions. The Univ. of Chicago Press.

Lance, C., G.E. Hobson, R.E. Young, and J.B. Biale. 1966. Metabolic processes in cytoplasmic particles of the avocado fruit. VII. Oxidative and phosphorylative activities throughou the climacteric. Plant Physiol. 40:1116-1123.

Lieberman, M., A.T. Kunishi, L.W. Mapson, and D.A. Wardale. 1965. Ethylene production from methionine. Biochem. J. 97:449-459.

Lyons, J.M. and J.K. Raison. 1970. Oxidative activity of mitochondria isolated from plant tissues sensitive and resistant to chilling injury. Plant Physiol. 45:386-389.

McMurchie, E.J., W.B. McGlasson, and I.L. Eaks. 1972. Treatment of fruit with propylene gives information about the biogenesis of ethylene. Nature (London) 237(5352):235-236.
Millerd, A. J. Bonner, and J.B. Giale. 1953. The climacteric rise in fruit respiration as controlled by phosphorylative coupling. Plant Physiol. 28(3):521-531.

Pearson, J.A. and R.N. Robertson. 1954. The physiology of growth in apple fruits. VI. The control of respiration rate and synthesis. Austral J. Biol. Sci. 7:1-17.

Rattanapanone, N., J. Speirs, and D. Grierson. 1978. Evidence for changes in messenger RNA content related to tomato fruit ripening. Phytochemistry 17:1485-1486.

Richmond, A. and J.B. Biale. 1966. Protein and nucleic acid metabolism in fruits: I. Studies of amino acid incorporation during the climacteric rise in respiration of the avocado. Plant Physiol. 41(8):1247-1253.

Richmond, A. and J.B. Biale. 1967. Protein and nucleic acid metabolism in fruits. II. RNA synthesis during the respiratory rise of the avocado. Biochem. Biophys. Acts 138:625-427.

Romani, R.J. 1984. Respiration, ethylene, senescence, and homeostasis in an integrated view of postharvest life. Can. J. Bet. 62:2950-2955.

Romani, R.J. 1987. Senescence and homeostasis in postharvest research. HortScience 22:865868.

Romani, R.J. and P.H. Howard, Jr. 1982. The restoration of mitochondrial membrane potential, oxidative phosphorylation and respiratory control, in vitro. Biochem. Intl. 4:369-375.

Romani, R.J., I.K. Yu, L.L. Ku, L.K. Fisher, and N. Dehgan. 1968. Cellular senescence, radiation damage to mitochondria, and the com- pensatory response in ripening pear fruits. Plant Physiol. 43(7):1089-1096.

Smith, C.J.S., C.F. Watson, J. Ray, C.R. Bird, P.C. Morris, W.S. Schuch, and D. Grierson. 1988. Antisense RNA inhibition of polygalacturonase gene expression in transgenic tomatoes. Nature (London) 334(6184):724-726.

Solomos, T. and G.G. Laties. 1976. Induction by ethylene of cyanide-resistant respiration. Biochem. Biophys. Res. Comm. 70:663-671.

Theologis, A. and G.G. Laties. 1978. Respiratory contribution of the alternate path during various stages of ripening in avocado and banana fruits. Plant Physiol. 62:249-255.

Tigchelaar, E. C., W.B. McGlasson, and R.W. Buescher. 1978. Genetic regulation of tomato fruit ripening. HortScience 13(5):508-513.

Ulrich, R. 1952. La vie des fruits. Masson et Cie Editeurs, Paris.

Yip, W-K, J-G Dong, J.W. Kenny, G.A. Thompson and S-F. Yang. 1990. Characterization and sequencing of the active site of 1-aminocyclopropane-1 -caroxylate synthase. Proc. Nat. Acad. Sci. 87:7930-7934.

Young, R.E. and J.B. Biale. 1951. Oxygen content of gases automatically recorded and measured to within 0.01 per cent. Food Processing 12(11):34.

Young, R.E. and J.B. Biale. 1967. Phosphorylation in avocado fruit slices in relation to the respiratory climacteric. Plant Physiol. 42:13571362.

Young, R. E., H.K. Pratt, and J.B. Biale. 1952. Manometric determination of low concentrations of ethylene. Anal. Chem. 24:551-555. 